\title{
ARE BROKERS' COMMISSION RATES ON HOME SALES TOO HIGH?
}

\section{A CONCEPTUAL ANALYSIS}

\author{
Paul Anglin ${ }^{\dagger}$ \\ and \\ Richard Arnott ${ }^{\dagger}$
}

September 1995

\begin{abstract}
Many people believe that prevailing commission rates for residential real estate brokers are "too high" but do not offer a formal model. This paper presents a general equilibrium model of the housing market in which real estate brokers serve as matching intermediaries. We use this model to construct an illustrative example which is "calibrated" using data representative of a typical housing market.
\end{abstract}

$\dagger$ Department of Economics

$\dagger \dagger$ Department of

Economics

Boston College

Chestnut Hill, MA 02167

N9B 3P4

USA

University of Windsor

Windsor, Ontario

CANADA 
(mailing address) 


\section{Are Brokers' Commission Rates On Home Sales Too High?}

\section{$\underline{\text { A Conceptual Analysis }}^{*}$}

The question posed in the title appears odd -- not to a layman, but to an economist. An economist trying to explain a price that was "too high" would look for the exercise of market power. But, at first glance at least, residential real estate brokerage appears highly competitive: entry and exit are virtually costless, average firm size is small, and licensing requirements are not onerous.

There is considerable dispute in the literature concerning the mechanism by which commission rates are determined. Broadly speaking, there are four classes of "models" -- none of which has been fully formalized. In the first, a competitive, symmetric information model, brokers compete over commission rate schedules based on local market conditions, offering better service for a higher commission rate. A home seller then chooses that commission rate/service quality pair from the competitively-determined commission rate schedule which maximizes his ${ }^{1}$ utility. The stylized facts appear inconsistent with the predictions of this model. If the model is realistic, one would expect to see a wide range of commission rate/service quality pairs; instead, one observes that residential commission rates in North America lie in a band between 5\% and $7 \%$ with little variation over time. The second class of models views the brokerage contract from a static principal-agent perspective, focusing on the inability of the seller (and the buyer) to monitor the agent's effort and to gauge the agent's ability. These models predict contractual diversity. A seller who wants to sell his home quickly should base the agent's remuneration on time to sale; a seller who requires a minimum amount of equity out of his home should offer a high-powered incentive contract which offers the agent a large bonus if the sales price is above that level which satisfies the equity requirement; and so on. While there is a trend towards contractual diversity, this class of model fails to explain why the commission contract remains dominant. The third class of

\footnotetext{
*Anglin would like to thank the Social Sciences and Humanities Research Council of Canada for its support. Arnott would like to thank seminar participants at Boston College, Harvard University, and the University of Melbourne, as well as Mak Arvin, for helpful comments. This draft of the paper was completed when Arnott was a Lusk Fellow at U.S.C. in May/June 1995. Arnott would like to thank the group there not only for being so hospitable but also for providing such a stimulating environment for "economic urbanologists."

1 Throughout, we treat buyers and sellers as male and real estate agents as female.
} 
models is similar, but takes the commission form of the contract as given. Since the commission contract has only a single parameter, ${ }^{2}$ it cannot "separate" agents. Since both agent quality and agent effort are unobservable, the seller will go with that agent offering the lowest commission rate. Commission rates will be bid down to the lowest possible quality of service, which does not at all accord with observation. The fourth class of models is based on collusion. Thirty years ago, local real estate boards set commission rates. Due to anti-trust action, they switched to recommending commission rates; and faced with further anti-trust action, they do not even do this now. How then can collusion be sustained? The story runs as follows. Most buyers use "selling agents" to assist them in searching listed properties. To sell a property, the seller's agent -- the "listing agent" -- requires the cooperation of selling agents. ${ }^{3}$ Thus, the blackballing of discount listing agents by selling agents can be effective in sustaining a collusive commission rate. Discount listing agents claim that such blackballing is common (Federal Trade Commission, 1983), and in some jurisdictions that they are also barred from listing under the Multiple Listing Service. Another factor in sustaining a collusive commission rate is that the significant minority of sellers do not realize -- and are not informed -- that the commission rate is negotiable. This class of models is consistent with the stylized facts but does not explain why one commission rate is chosen over another. Apart from these models, there is a widely-held view that reputation plays an important role in the market in providing agents with an incentive to provide quality service.

In short, there are no complete and persuasive models of how the commission rate is determined. Thus, to investigate whether the commission rate is too high, a conceptualization is needed that is independent of how the commission rate is actually set. Furthermore, because of the externalities endemic to search models, the socially optimal commission rate will in general differ from the commission rate thrown up by the market, however determined.

\footnotetext{
${ }^{2}$ This is not strictly correct. There are two other parameters, the period of the listing agreement and the listing price. According to this class of models, the period of the listing agreement is irrelevant since, if there are any costs to switching agents, the seller will relist with the same agent; the listing price is irrelevant too, since the buyer can make an offer at any price he wishes. ${ }^{3}$ Using the data described in Anglin (1994) for Windsor, Canada, it is possible to gauge the importance of cooperation. 36 percent of properties were listed with the top four firms, and on at least 50 percent of all transactions either the listing agent or the selling agent or both were employed by one of these firms.
} 
For this reason, it is necessary to employ a general equilibrium model. ${ }^{4}$ This paper presents such a model in which real estate agents are matching intermediaries, matching buyers with houses. Observing how the market performs (e.g., proportion of homes for sale, average time to sell, average time to buy, number of full-time-equivalent agents) one can make inferences concerning the matching technology. And with knowledge of the matching technology, the optimal commission rate can be determined and compared to the prevailing rate.

Section 1 presents a model of the housing market with real estate agents, and investigates the existence and uniqueness of equilibrium, as well as its comparative static properties, taking the commission rate as a datum. Section 2 describes the normative framework for determining the socially optimal commission rate and illustrates how the model can be calibrated or estimated using aggregate market data. We then illustrate how the calibrated model can be used to compute the socially optimal commission rate. Section 3 concludes with a discussion of directions for future research.

Although the paper focuses on the housing market, the same issues arise in other markets in which search intermediaries play a role; for example, the commissions paid to travel agents, to job search services, whether private "head hunters" or government-sponsored agencies (Osberg, 1993, Section VI), and to retail sales persons are amenable to the same type of analysis.

\section{The Basic Model}

The model adapts the rental housing market model ${ }^{5}$ presented in Igarashi (1991), which in turn draws on labor-market matching models, especially

\footnotetext{
${ }^{4}$ In recent years, a large number of papers have been published on the economics of residential real estate brokerage, particularly on the form of the brokerage contract (recent contributions include Anglin and Arnott (1991), Miceli (1992) and Yavas (1994)). Unfortunately, with the exception of Yinger (1981) and Fu (1993), the models in all these papers are partial equilibrium in nature and hence inappropriate for addressing the question at issue in this paper. A few papers examine empirically the determinants of the commission rate, such as Sirmans, Turnbull and Benjamin (1991). ${ }^{5} \mathrm{Fu}$ (1993) independently developed a model that is similar to ours. Using a matching model where agents can enter freely, Chapter 2 in Fu (1993) characterizes the optimal commission rate. His analysis focuses on the effect of the commission rate on the number of agents and on the effort per agent: viz., maximizing the aggregate matching rate at a given cost requires that the relative marginal products of an additional agent and of additional effort should equal their
} 
Diamond (1981) and Hosios (1990), and on Arnott's model of thin rental housing markets with idiosyncrasy (1989). The two essential features of the model are idiosyncrasy and matching. Combining these two features generates an analytically neat treatment of housing search.

\subsection{Broad-brush description}

Households have idiosyncratic tastes and houses differ in idiosyncratic ways. Furthermore, these idiosyncrasies are symmetric in the following sense. Houses all cost the same to construct. Each household has an ideal house of this construction cost. If he resides in some other type of house, he experiences a mismatch cost. Idiosyncrasies are symmetric in the sense that the probability distribution of the mismatch cost for an arbitrarily-selected house and an arbitrarily-selected household is independent of the house and the household.

Search is represented by an aggregate matching function. Let $B$ be the stock of home buyers, $S$ the stock of houses for sale, $A$ the number of real estate agents, and $g$ the effort expended by a representative agent. Then search generates $m=m(B, S, A, g)$ aggregate opportunities to match per period, or more precisely an aggregate Poisson opportunity-to-match rate of $m$. By symmetry, each home buyer receives opportunities to match at the Poisson rate $\frac{m}{B}$ and each house seller at the rate $\frac{m}{s}$. The details of the search process, including what it is that agents do -- apart from exerting effort -- are suppressed. Associated with a particular opportunity to match is a draw from the probability distribution of mismatch costs. The full price associated with an opportunity to match equals the market price of the unit plus the discounted mismatch costs associated with the opportunity to match. The housing market will be assumed to be in a steady state. As a result, households will adopt a time-invariant reservation full price rule under which they will purchase a house that they have been matched with if its full price is below the reservation full price and not otherwise.

In the basic model, households enter the housing market but do not exit. The rate of entry is proportional to the housing market population. This, combined with assumptions that housing construction and the matching

relative marginal social costs. In contrast, our model focuses on the effect of the commission rate on the number of buyers, sellers, and agents and on how each contributes to the aggregate matching rate. 
technology exhibit constant returns to scale, leads to a steady-state equilibrium in which the housing market grows exponentially over time, without changes in relative magnitudes.

Households choose the reservation full price to minimize the expected present value of accommodation costs, the sum of expected discounted search and homeownership costs. Builders construct houses and charge a price ${ }^{6}$ to maximize expected discounted profits, taking into account that a higher-priced house is likely to take longer to sell. Free entry and exit in the construction business leads to zero expected profits. Real estate agents choose sales effort, and free entry and exit in residential real estate brokerage forces brokers' utility down to its reservation level. When a house is sold, the builder pays the broker a commission equal to the commission rate times the sale price. The commission rate is fixed exogenously.

This basic model is descriptively unrealistic in a number of respects: only newly-constructed houses are sold; there is no exit of households; households and houses are identical, apart from idiosyncratic differences; there is no housing depreciation or maintenance; and there is no land. The purpose of starting with a descriptively unrealistic model is to present the structure as starkly as possible. Some extensions in the direction of realism will be discussed in section 3 .

\subsection{Full description}

The population of households in the housing market is normalized at one:

$$
B+\mathbb{B}=1,
$$

where $B$ is the stock of home buyers and $\mathbb{B}$ the stock of homeowners. The housing market is in steady state with the population growing at rate $n$. There is entry of households into the housing market but no exit.

\footnotetext{
${ }^{6}$ We chose this exchange mechanism because it is simple and because Igarashi (1991) and Arnott (1989) employed it successfully in analyzing the rental housing market. Observation suggests, however, that while take-it-or-leave-it pricing is standard in the rental housing market, bargaining is the norm in the owner-occupied housing market. We did investigate replacing take-it-or-leave-it pricing with bargaining in our model and found that doing so generated more heat than light. In any event, simply assuming the form of the exchange mechanism is unsatisfactory -- it should be made endogenous. See Peters (1994) and the references therein for work along these lines.
} 
In equilibrium, all builders choose the same housing price. The household's reservation full price rule for purchasing a home therefore reduces to a reservation mismatch cost rule. Hence, where $X$ is the per-period mismatch cost, $F(X)$ the cumulative distribution function of mismatch cost (with $f(\cdot)$, which is assumed to be continuous, its derivative, and $\mathfrak{J}(\cdot)$ its integral) and $X^{*}$ the reservation mismatch cost, a proportion $F\left(X^{*}\right)$ of opportunities to match result in a successful match -- a home purchase. Thus, where $m=m(B, S, A, g)$ is the aggregate rate of opportunities to match, $m F\left(X^{*}\right)$ is the aggregate rate of transactions. The stock of home buyers grows at the rate $\dot{B}=n-m F\left(X^{*}\right)$, since households enter the pool of homebuyers at rate $n$ and exit it at rate $m F\left(X^{*}\right)$. A steady-state requirement is that $\dot{B}=n B$. Combining these two conditions yields the steady-state equilibrium condition

$$
n(1-B)-m F\left(X^{*}\right)=0 .
$$

We now turn to the household's reservation full price decision. Let $C^{B}$ be the expected present value of accommodation costs for a homebuyer, which includes discounted search costs prior to home purchase, the discounted home purchase price, and discounted mismatch costs subsequent to home purchase. In making this decision, the household takes the market price of a house, $P$, as given. Thus, its reservation full price decision reduces to a reservation mismatch cost decision, with the reservation mismatch cost depending on the market price. Let $r$ be the discount rate, $b$ be per-period search costs (which include the costs of living in temporary accommodation), $\bar{X}\left(X^{*}\right)$ be the expected mismatch cost as a function of the reservation mismatch $\operatorname{cost}\left(\bar{X}\left(X^{*}\right)=\int_{0}^{X^{*}} X f(X) d X / F\left(X^{*}\right)\right)$, and $T^{B}$ be the time spent searching, a random variable. Then

$$
C^{B}=\mathfrak{E}_{T^{B}}\left\{\int_{0}^{T^{B}} b e^{-r t} d t+P e^{-r T^{B}}+\int_{T^{B}}^{\infty} \bar{X}\left(X^{*}\right) e^{-r t} d t\right\},
$$

where $\mathfrak{E}_{T^{B}}\{\cdot\}$ represents the expectation with respect to time-to-buy. Since home purchase occurs according to a Poisson process with arrival rate $\frac{m F\left(X^{*}\right)}{B}$, the probability that $T^{B}$ is in the interval $(t, t+d t)$ is $\frac{m F\left(X^{*}\right)}{B} \exp \left(\frac{-m F\left(X^{*}\right) t}{B}\right) d t$. Then straightforward calculation yields 


$$
C^{B}=\frac{b+\frac{m F\left(X^{*}\right)}{B}\left(P+\frac{\bar{X}\left(X^{*}\right)}{r}\right)}{\frac{m F\left(X^{*}\right)}{B}+r} .
$$

The household chooses $X^{*}$ to minimize $C^{B}$, resulting in the intuitive reservation mismatch cost rule that the reservation full price equal the expected costs of continuing search:

$$
C^{B}=P+\frac{X^{*}}{r}
$$

(The second order condition for a minimum is satisfied.) Combining the above two equations yields

$$
\frac{b+\frac{m F\left(X^{*}\right)}{B}\left(P+\frac{\bar{x}\left(X^{*}\right)}{r}\right)}{\frac{m F\left(X^{*}\right)}{B}+r}-P-\frac{X^{*}}{r}=0,
$$

which is an implicit function characterizing a household's reservation mismatch cost as a function of the market price for a house.

Next we examine behavior in the construction sector. The representative builder chooses $P$ to maximize the expected discounted value of profits from building a house taking the household reservation full price, $P+\frac{X^{*}}{r}$, as given. Let $P_{o}$ be the price charged by the builder. The builder knows that a prospective buyer will purchase the house if and only $P_{o}+\frac{X}{r}=P+\frac{X^{*}}{r}$, which occurs with probability $F\left(r P+X^{*}-r P_{o}\right)$. Therefore, where $K$ is the construction cost of a house, $\phi$ the commission rate, and $T^{s}$ the time the house is on the market, a random variable, his maximization problem is

$$
\max _{P_{o}} \Pi=\mathbb{E}_{T^{s}}\left\{(1-\phi) P_{o} e^{-r T^{s}}\right\}-K
$$

Since house sale occurs according to a Poisson process with arrival rate $\frac{m F\left(r P+X^{*}-r P_{o}\right)}{S}$, this problem can be rewritten as

$$
\max _{P_{o}} \Pi=(1-\phi) P_{o} \frac{\frac{m F\left(r P+X^{*}-r P_{o}\right)}{S}}{\frac{m F\left(r P+X^{*}-r P_{o}\right)}{S}+r}-K .
$$


Expected discounted profit maximization reduces to expected discounted revenue maximization and yields an obvious first-order condition. ${ }^{7}$ Since all builders have the same cost and take the households' reservation full price as given, they all choose the same $P_{o}$. Consistency then requires that the price builders choose is the price households take as given, i.e. $P=P_{o}$. Incorporating this condition into the first-order condition yields

$$
F\left(X^{*}\right)\left(m F\left(X^{*}\right)+r S\right)-P^{2} S f\left(X^{*}\right)=0 .
$$

Free entry and exit implies zero profits:

$$
((1-\phi) P-K) m F\left(X^{*}\right)-r S K=0 .
$$

The above two equations can be combined to yield

$$
P=\frac{K}{1-\phi}+\frac{F\left(X^{*}\right)}{r f\left(X^{*}\right)}
$$

Finally, we turn to residential real estate agents. It is assumed that the matching rate achieved by a particular agent is $\frac{m}{A} \frac{g_{o}}{g}$, where $g_{o}$ is the particular agent's effort and $g$ is the market level of effort which each agent takes as exogenous. This implies that an increase in the effort of an individual agent increases her sales but not the aggregate matching rate. The agent's cost of effort is $C(g), C(0)=0, C^{\prime}>0, C^{\prime \prime}>0$, which can be interpreted either as the disutility of effort or advertising expenditures. An agent perceives her income to be

$$
\frac{\phi m P F\left(X^{*}\right)}{A}\left(\frac{g_{o}}{g}\right)-C\left(g_{o}\right) .
$$

The first-order condition of her effort choice problem is straightforward. Since each agent faces the same maximization problem, consistency requires that $g_{o}=g$. Combining these two conditions yields

$$
\frac{\phi m P F\left(X^{*}\right)}{A}-C^{\prime}(g) g=0 .
$$

\footnotetext{
${ }^{7}$ The second-order condition is $-2 f^{2}+F f^{\prime}<0$. We assume it to be satisfied.
} 
An agent's reservation income in an occupation in which she expends minimal $(g=0)$ effort is $\hat{w}$, which is assumed to be exogenous. Free entry and exit will drive agents' income to this reservation income. Hence,

$$
\frac{\phi m P F\left(X^{*}\right)}{A}-C(g)=\hat{w} .
$$

The above two equations imply that the equilibrium level of $g, g^{*}$, is the unique solution to $\hat{w}=C^{\prime}(g) g-C(g)$, which is independent of market conditions. ${ }^{8}$ Letting $w \equiv \hat{w}+C\left(g^{*}\right)$, the above equation can be written as

$$
\frac{\phi m P F\left(X^{*}\right)}{A}-w=0
$$

where $w$ is the income the agent must receive to be indifferent between being a real estate agent and taking reservation employment.

Equations (1) - (5) give 5 equations in 5 unknowns, $B, X^{*}, P, S$, and $A$. $B$ enters only in (1), $S$ only in (3), and $A$ only in (5). Thus, the equations can be simply reduced to 2 equations in $X^{*}$ and $P,(4)$ and

$$
b-\frac{m F\left(X^{*}\right)}{\left(1-\frac{m F\left(X^{*}\right)}{n}\right) r}\left(X^{*}-\bar{X}\left(X^{*}\right)\right)-r P-X^{*}=0,
$$

where

$$
m=m\left(1-\frac{m F\left(X^{*}\right)}{n}, \frac{((1-\phi) P-K) m F\left(X^{*}\right)}{r K}, \frac{\phi m P F\left(X^{*}\right)}{w}, g^{*}\right) .
$$

Substitution of ( $\left(2^{\prime}\right)$ into the above equation gives

$$
m=m\left(\frac{m F\left(X^{*}\right)\left(X^{*}-\bar{X}\left(X^{*}\right)\right)}{r\left(b-r P-X^{*}\right)}, \frac{((1-\phi) P-K) m F\left(X^{*}\right)}{r K}, \frac{\phi m P F\left(X^{*}\right)}{w}, g^{*}\right) .
$$

${ }^{8}$ This aspect of the model is unfortunate because it implies that an increase in the commission rate, $\phi$, increases the number of agents but has no effect on the level of effort. Thus, our model cannot address the question of whether an excessive commission rate causes underemployment of agents. 
Since $m(\cdot)$ is, by assumption, homogenous of degree one in its first three arguments, the above equation reduces to

$$
1-F\left(X^{*}\right) m\left(\frac{X^{*}-\bar{X}\left(X^{*}\right)}{r\left(b-r P-X^{*}\right)}, \frac{(1-\phi) P-K}{r K}, \frac{\phi P}{w}, g^{*}\right)=0,
$$

except when $m F\left(X^{*}\right)=0$ in (7), in which case (2') and (6) must be employed. We shall refer to $m(\cdot)$ in (7) as the normalized matching function, and when its arguments are suppressed shall denote it by $\tilde{m}$.

To simplify subsequent notation, we let define

$$
\begin{aligned}
& G\left(X^{*}, P ; r, b, \phi, K, w, g^{*}, F(\cdot)\right) \equiv 1-F\left(X^{*}\right) m\left(\frac{X^{*}-\bar{X}\left(X^{*}\right)}{r\left(b-r P-X^{*}\right)}, \frac{(1-\phi) P-K}{r K}, \frac{\phi P}{w}, g^{*}\right) \\
& I\left(X^{*}, P ; r, \phi, K, F(\cdot)\right) \equiv P-\frac{K}{1-\phi}-\frac{F\left(X^{*}\right)}{r f\left(X^{*}\right)} .
\end{aligned}
$$

$I(\cdot)=0$ incorporates the builder's first-order condition and zero-profit condition. $G(\cdot)=0$ incorporates the steady-state condition, the household's choice of $X^{*}$, the builder's zero-profit condition, and the real estate agent's effort-choice decision, and entry equilibrium condition. The rest of this section is devoted to exploring the properties of $G(\cdot)=0$ and $I(\cdot)=0$.

We shall employ the following assumptions:

Assumption $1: \frac{b}{r} \geq \frac{K}{1-\phi}$

Assumption 2: i) $\frac{F}{f}$ is increasing ${ }^{9}$ in $X$, implying ${ }^{10}$ that $\frac{\mathbb{f}}{F}$ is increasing in $X$;

ii) $\lim _{x \downarrow 0} \frac{F}{f}=0$

\footnotetext{
${ }^{9}$ Note that this implies that the second-order condition of the builder's maximization problem is satisfied. See fn. 3 .

${ }^{10}$ Strict log-concavity is preserved under integration (see Caplin and Nalebuff (1991)). Thus, $\mathfrak{f}$ is strictly log-concave, which generates the following string of equivalencies: $\mathfrak{f}$ strictly log-concave \& $\frac{d\left(\frac{\mathbb{H} F}{F}\right)}{d X^{*}}>0 \not F^{2}-f \mathfrak{H}>0 \not x \frac{d\left(X^{*}-\bar{X}\right)}{d X^{*}}>0$.
} 
Assumption 3: i) $m(0, . . .,)=0,. m(., 0, . .)=$.0 ; ii) $m_{i}>0, i=1, \ldots, 4$; iii) $m_{i i}<0$, $m_{i j}>0, i, j=1, \ldots, 3$, where subscripts denote partial derivatives.

Assumption 1 states that search costs exceed amortized gross-of-commission construction costs. Assumption 2 is that $F(\cdot)$ is strictly log-concave. Assumption 3 states that the matching function has the properties of a regular production function over "inputs" $B, S$, and $A$, and that $B$ and $S$ are essential in production.

Assumption 2 implies that $I(\cdot)=0$ has the following properties

$$
I\left(0, \frac{K}{1-\phi}\right)=\left.0 \quad \frac{d P}{d X^{*}}\right|_{I=0}=\frac{\frac{d}{d X}\left(\frac{F\left(X^{*}\right)}{f\left(X^{*}\right)}\right)}{r}>0 .
$$

We also have the following properties for $G(\cdot)=0$ :

$$
G\left(0, \frac{b}{r}\right)=0 \quad G\left(b-\frac{r K}{1-\phi}, \frac{K}{1-\phi}\right)=0,
$$

and for those $X^{*}$ and $P$ for which the matching rate is positive $\left(X^{*}>0\right.$ and $\left.P>\frac{K}{1-\phi}\right)$

$$
\left.\frac{d P}{d X^{*}}\right|_{G=0}=-\frac{-f \tilde{m}-F \tilde{m}_{1}\left(\frac{X^{*}-\bar{X}}{r\left(b-r P-X^{*}\right)^{2}}+\frac{d\left(X^{*}-\bar{X}\right) / d X^{*}}{r\left(b-r P-X^{*}\right)}\right)}{-F\left(\tilde{m}_{1} \frac{\left(X^{*}-\bar{X}\right)}{\left(b-r P-X^{*}\right)^{2}}+\tilde{m}_{2} \frac{(1-\phi)}{K}+\tilde{m}_{3} \frac{\phi}{w}\right)}<0
$$

and

$$
\left(X^{*}+r P-b\right)_{G(\cdot)=0}<0
$$

Eqs. (11a) and (11b) are obtained from (2') and (6) (since at both points the aggregate matching rate is zero). The inequality (11c) follows from Assumption 2i) -- see fn. 8 -- and (11d) follows from (2') and states that expected discounted accommodation costs in the search pool are less than the costs of searching forever. 
From these properties of $G(\cdot)=0$ and $I(\cdot)=0$, it is straightforward to show that equilibrium exists and is unique. Figure 1 portrays $G(\cdot)=0$ and $I(\cdot)=0$ in $\frac{X^{*}}{r}-P$ space, using the parameters of the numerical example which are listed in Table 2.

\section{INSERT FIGURE 1 HERE}

There are numerous distortions in the model. There are the familiar search externalities. Neither households when they choose $X^{*}$, nor builders when they choose to build and to set the price, nor real estate agents when they choose effort and entry, take into account the effect of their actions on the aggregate matching rate. Builders exploit their market power in setting prices. Agents are subject to a rat race externality in their choice of effort. And the commission rate itself is distortionary. Igarashi and Arnott (1995) provide a reasonably full analysis of the analogous externalities for the rental housing market. For this paper, we note simply that the optimal commission rate is the optimal rate for a highly distorted economy, and can be viewed as balancing the "right" number of real estate agents against mitigating distortions.

We now turn to the comparative static properties of equilibrium. The results are derived in Appendix 1 and presented in Table 1. $\xi$ measures the efficiency of the matching process, entering $G(\cdot)=0$ as $1-F \xi \tilde{m}=0$. The table presents no surprises and the results are readily explainable. For reasons of space, we shall discuss only the effects of a change in the commission rate. A rise in $\phi$

Table 1

\section{Comparative Statics}

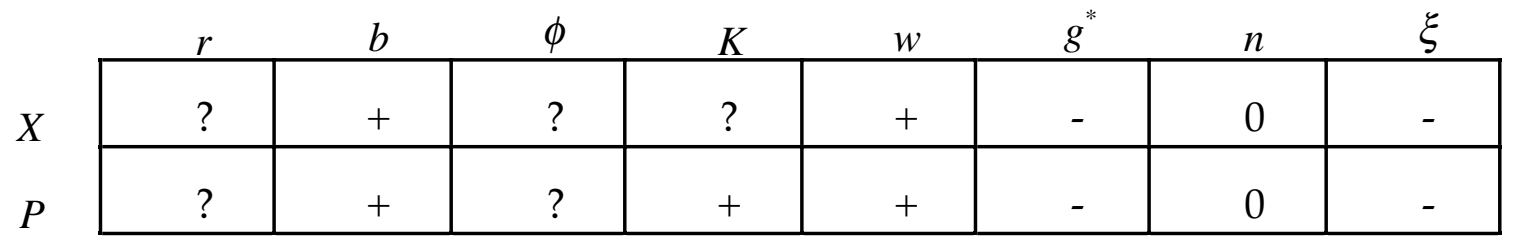

cause the $I(\cdot)=0$ curve to rotate counterclockwise; holding $X^{*}$ fixed, to restore zero profits for builders requires a rise in price. Its effect on $G(\cdot)=0$ is, however, ambiguous. The intuition is that, holding $P$ and $X^{*}$ fixed, the rise in the commission rate requires that the number of houses for sale fall (to continue 
satisfying the zero profit condition for builders) and causes the number of agents to rise. The former effect decreases the matching rate, the latter increases it. If the former effect dominates, then, holding $P$ fixed, $X^{*}$ must rise in order that (7) continue to hold, so that $G(\cdot)=0$ bulges out. In this case, the shifts in $I(\cdot)=0$ and $G(\cdot)=0$ combine to increase the equilibrium price while the equilibrium value of $X^{*}$ can rise or fall. If the latter effect dominates, price may either rise or fall, but the reservation mismatch cost unambiguously falls.

\section{Normative Properties of the Model}

\subsection{The optimal commission rate}

Varying the commission rate generates a locus of equilibrium points in $\left(\frac{X^{*}}{r}, P\right)$ space, $\Gamma\left(\frac{X^{*}}{r}, P\right)=0$. We wish to determine which of these points is optimal and, from this, what the optimal commission rate is. What can be said about this locus? It is continuous and lies inside the triangle with vertices $\left(0, \frac{K}{1-\phi}\right),\left(0, \frac{b}{r}\right)$ and $\left(\frac{b}{r}-\frac{K}{1-\phi}, \frac{K}{1-\phi}\right)$. Also, since a rise in the commission rate rotates $I(\cdot)=0$ counterclockwise but has an ambiguous effect on $G(\cdot)=0$, the locus cannot intersect itself. These restrictions are not very restrictive.

What is the appropriate criterion to judge between alternative commission rates? Since builders make zero profits and real estate agents earn their opportunity wage, social costs equal the expected present value of accommodation costs, $C^{B}$, and the optimal commission rate is that which minimizes these costs. We already know from the first-order condition with respect to $X^{*}$ of the household's cost-minimization problem, that $C^{B}=P+\frac{X^{*}}{r}$. Thus, determination of the optimal commission rate has a neat geometric interpretation (see Figure 2 which employs the parameters of the example) because social cost contours have a slope of -1 in $\left(\frac{X^{*}}{r}, P\right)$ space.

\section{INSERT FIGURE 2 HERE}

The optimum, indicated by $Z$ in the Figure, occurs at the point of lowest social cost on $\Gamma\left(\frac{X^{*}}{r}, P\right)$. Algebraically, the optimal commission rate solves 


$$
\begin{array}{r}
\min _{X, P, \phi} C^{B}=\frac{X^{*}}{r}+P \\
\text { s.t. i) } G(\cdot)=0 \\
\text { ii) } I(\cdot)=0 .
\end{array}
$$

Substituting out $P$ from $I(\cdot)=0$ and using $(8)$, this problem becomes

$$
\begin{gathered}
\min _{X^{*}, \phi} \frac{X^{*}}{r}+\frac{K}{1-\phi}+\frac{F\left(X^{*}\right)}{r f\left(X^{*}\right)} \\
1-F\left(X^{*}\right) m\left(\frac{X^{*}-\bar{X}\left(X^{*}\right)}{r\left(b-\frac{r K}{1-\phi}-\frac{F\left(X^{*}\right)}{f\left(X^{*}\right)}-X^{*}\right)}, \frac{(1-\phi) F\left(X^{*}\right)}{r^{2} K f\left(X^{*}\right)}, \frac{\phi\left(\frac{K}{1-\phi}+\frac{F\left(X^{*}\right)}{r f\left(X^{*}\right)}\right)}{w}, g^{*}\right)=0 .
\end{gathered}
$$

\subsection{Illustrative calibration}

In this subsection, we show how the model can be calibrated on the (unrealistic) assumption that the model provides a true description of reality. For a particular housing market, information is readily available on the interest rate, the population growth rate, the volume of sales, average sales price, mean time to sale for houses, mean time on the market for buyers, the average commission rate, and the number of full-time-equivalent real estate agents. We wish to employ such data to estimate the unknowns -- construction costs, and characteristics of the matching function and of the c.d.f. of mismatch costs. The procedure is similar to that employed by Blanchard and Diamond $(1990,1991)$ for the labor market.

Taking dollars and years as our units of measurement, suppose ${ }^{11}$ that we observe a housing market in which $r=.05, n=.04, \phi=.06$, mean time to buy $=$ $\frac{B}{m F}=.3^{\circ}$ (4 months), mean time to sell $=\frac{S}{m F}=.25$ (3 months), $P=\$ 100000$, and $w$ $=\$ 40000$. Then, from (1), $m F=.0394737$, implying that $B=.0131579$ and $S=$ .0098643; from (5), $A=.00592105$; from (3), $K=92839.5$; and from (4), $\frac{F}{f}=$ 61.7287. That leaves us with (2). Assume that $F(X)$ has the form ${ }^{12} F(X)=c_{0} X^{\delta}$.

${ }^{11}$ The numbers were chosen to be broadly consistent with average market data reported in National Association of Realtors (1991).

${ }^{12}$ Arnott (1989) provides a theoretical justification for this assumption, with $\delta$ being interpreted as the effective dimensionality of the characteristics space. 
Then $\bar{X}=\frac{\delta}{\delta+1} X^{*}, X^{*}-\bar{X}=\frac{1}{\delta+1} X^{*}$, and $\frac{F}{f}=\frac{X^{*}}{\delta}$. If $b$ is measurable, then (2) and $\frac{X^{*}}{\delta}=$ 61.7287 provide two equations in $X^{*}$ and $\delta$. If, for example, $b=9488.37$, then $X^{*}$ $=1000$ and $\delta=16.20$, implying that $\bar{X}=941.860$. If $b$ is not measurable, then observation of two equilibria would permit the simultaneous determination of the $X^{* \prime}$ s for both equilibria, as well as $b$ and $\delta$.

The concept of an "opportunity to match" is useful in the development of the theory but is not empirically operational. One could make the concept concrete by defining an opportunity to match as the viewing of an advertisement, an inquiry put to a real estate agent concerning a property, or an inspection. But data on these magnitudes are generally not available. Note, however, that the matching function $m(\cdot)$ always enters as $F\left(X^{*}\right) m(\cdot)$. Thus, the theory can be recast in terms of a "successful match" or sales function $\sigma\left(X^{*}, B, S, A, g\right)$. Sales are observable, as are $B, S$, and $A ; g$ can be suppressed since the theory predicts that it is constant; and $X^{*}$ can be inferred per the procedure employed in the previous paragraph. Thus, $\sigma(\cdot)$ is estimable empirically.

To solve for the sales function would require data for different equilibria. If the sales function were the same across cities, cross-section data could be employed. If the sales function were constant over time, times series data could be used. Suppose, for the sake of illustration, that the sales function is $\sigma\left(X^{*}, B, S, A\right)=c\left(X^{*}\right)^{16.2} B^{4} S^{4}{ }^{4}{ }^{2}{ }^{2}$, with $c=9.9187 \tilde{\mathrm{A}} 10^{-49}$, which is consistent with the numerical example. Then, with the assumed parameters, from (12') the optimal commission rate is $.28 \%$. We attach little practical significance to this figure since the elasticities of the matching function were assumed rather than estimated and since the underlying model is unrealistically simple. Further, this commission rate is far below the rate offered in any housing market in the world. The example is nevertheless of interest because it illustrates a general procedure that can be employed to estimate the optimal commission rate. It is also instructive in illustrating how a change in the commission rate impacts the housing market. The results of the example are shown in Table 2. The most striking feature of the example is how little effect the reduction in the commission rate from $6 \%$ to $.28 \%$ has on the number of buyers, the number of sellers, expected time to buy, and expected time to sell. Buyers simply become somewhat less fussy in their choice housing. 
Table 2

Numerical Examples

Exogenous parameters (units: yrs., \$)

$$
\begin{array}{lll}
r=.05 & b=9,488.37 & \gamma=0.2 \\
n=.04 & \delta=16.2 & c=9.9187 \tilde{\mathrm{A}} 10^{-49} \\
w=40000 & \alpha=0.4 & \\
K=92,839.5 & \beta=0.4 &
\end{array}
$$

Results

$\begin{array}{lrc} & \begin{array}{l}\text { Base Case } \\ (\phi=.06)\end{array} & \begin{array}{c}\text { Optimum } \\ (\phi=.0028)\end{array} \\ C^{B} \text { (social cost) } & 120,000 & 115,136 \\ P & 100,000 & 94,381 . \\ X^{*} & 1,000 & 1037.7 \\ B & 0.01316 & 0.01277 \\ S & 0.00985 & 0.01087 \\ A & 0.00592 & 0.0002609 \\ \frac{B}{m F} \text { (expected time to buy) } & 0.3 & 0.3234 \\ \frac{S}{m F} \text { (expected time to sell) } & 0.25 & 0.2752\end{array}$

\section{Concluding Comments}

We first discuss ways in which the model can be extended to improve its realism for empirical application. 


\subsection{Directions for future research}

The model can be extended to treat exit from the market, as well as mobility within the market. A simple way to treat these phenomena is as follows. Assume that a household receives a signal to exit (according to a Poisson process with rate $\mu$ ) and another signal which triggers a change in taste (according to a Poisson process with rate $\theta$ ), perhaps due to a change in the household's composition, that requires an owner-occupying household to move within the market. A household knows only the stochastic process generating these signals. Assume that when a household receives a signal, it moves immediately and puts its unit on the market; assume also that housing markets are symmetric, so that the number of households entering a housing market equals the number exiting the market plus that market's share of newly-formed households.

Under these assumptions, eqs. (3) - (5) are unchanged. Eq. (1) is replaced by ${ }^{13}$

$$
(n+\theta+\mu)(1-B)-m F=0 .
$$

Eq. (2) is replaced by

$$
\frac{b\left(\frac{r+\mu+\theta}{r}\right)+\frac{m F}{B}\left(P \Xi+\frac{\bar{X}}{r}\right)}{\frac{m F}{B}+r+\mu+\theta}-P \Xi-\frac{X^{*}}{r}=0
$$

where

$$
\Xi=\frac{r+\mu+\theta+\frac{m F}{S}\left(1+\frac{\phi(\mu+\theta)}{r}\right)}{\frac{m F}{S}+r}>1 .
$$

Reducing this system of equations yields two equations, (4) and

$$
(r+\mu+\theta)\left(\frac{b}{r}-P \mathfrak{A}-\frac{X^{*}}{r}\right)-\frac{m F(n+\theta+\mu)}{(n+\theta+\mu-m F)}\left(\frac{X^{*}}{r}-\frac{\bar{X}}{r}\right)=0,
$$

in two unknowns, where

${ }^{13}$ The derivations are presented in Appendix 2. 


$$
\mathfrak{A}=\frac{r+\mu+\theta}{r}-\frac{(\mu+\theta) K}{r P}
$$

and

$$
m=m\left(1-\frac{m F\left(X^{*}\right)}{n+\theta+\mu}, \frac{((1-\phi) P-K) m F\left(X^{*}\right)}{r K}, \frac{\phi m P F\left(X^{*}\right)}{n}, g^{*}\right)
$$

This treatment of exit and internal mobility is tractable but not completely satisfactory. First, the decisions to exit the market or to move within the market are in fact endogenous. One would expect $\mu$ and $\theta$ to depend on the commission rate, since a higher commission rate has a lock-in effect. As well, even with ex ante homogeneous households, one would expect that households would acquire some information during the search process concerning their future exit or internal mobility, which would affect their choice of $X^{*}$. Second, a homeowner's decision concerning whether to move immediately upon receiving a signal or to stay until the home is sold (or to adopt some intermediate strategy) should be endogenized. ${ }^{14}$

This model is unrealistic in another way because it ignores the rental sector. There are several linkages between the rental and owner-occupied housing market. Not all households that enter the market aim to own their residence, at least not immediately; there is mobility within the market between the rental and owner-occupied submarkets; and real estate agents operate in both submarkets. The simplest way to treat the two submarkets simultaneously is to assume that a household is assigned to a submarket by an exogenous stochastic processes. Assume that a proportion $q$ of entrants to the housing market aim to

${ }^{14}$ The model with internal mobility and no exit is similar to that of Wheaton (1990). The model of Wheaton's paper differs from ours in the following respects: i) it focuses on the short run in which the stock of houses is fixed (which is why, in contrast to our model, housing price is so sensitive to the vacancy rate); ii) it treats only two housing types so that households are either matched or mismatched; iii) housing price is determined by bargaining; and iv) when a homeowner becomes mismatched with his home, he does not put his "old" home on the market until he has found a "new" home, which assumes that he stays in his old home until he has found a new home. With regard to the difference between Wheaton's assumptions iii) and iv) and the corresponding assumptions in our model, each pair of assumptions is equally arbitrary (though they may differ in their realism). A more satisfying treatment would make both the price determination mechanism and the household's decision concerning when to start searching for a new home, to move, and to list the old home endogenous. In contrast to our model (with the assumption of the log-concavity of $F($.$) ), in Wheaton's model there may be multiple equilibria.$ 
rent, that a household in the rental submarket (whether renting or in the rental search pool) switches to the owner-occupied search pool at the Poisson rate $\rho$, and that a household in the owner-occupied submarket (whether owning or in the owner-occupied search pool) switches to the rental search pool at the Poisson rate $\omega$. As in the basic model, assume that a household vacates its unit as soon as it receives a signal to change its state. Let $D$ be the proportion of households that are renters and $E$ the proportion that are in the rental search pool. Account also needs to be taken of search in the rental housing market. Modeling this analogously to search in the owner-occupied housing market, let $M\left(E, V, A^{\prime}, g^{\prime}\right)$ be the aggregate rate of opportunities to match in the rental submarket with $V$ the number of vacant rental units, $A^{\prime}$ the number of real estate agents operating in the rental submarket, and $g^{\prime}$ the effort each expends. Also, let $Y$ be rental mismatch costs with cdf $H(Y)$. Finally, as with the owner-occupied submarket, exit from the market (at proportional Poisson rate $\mu$ ) and mobility within the rental sector (at proportional Poisson rate $\lambda$ ) can be treated. The flows between the various household states, under these assumptions, are given in Figure 3 below.

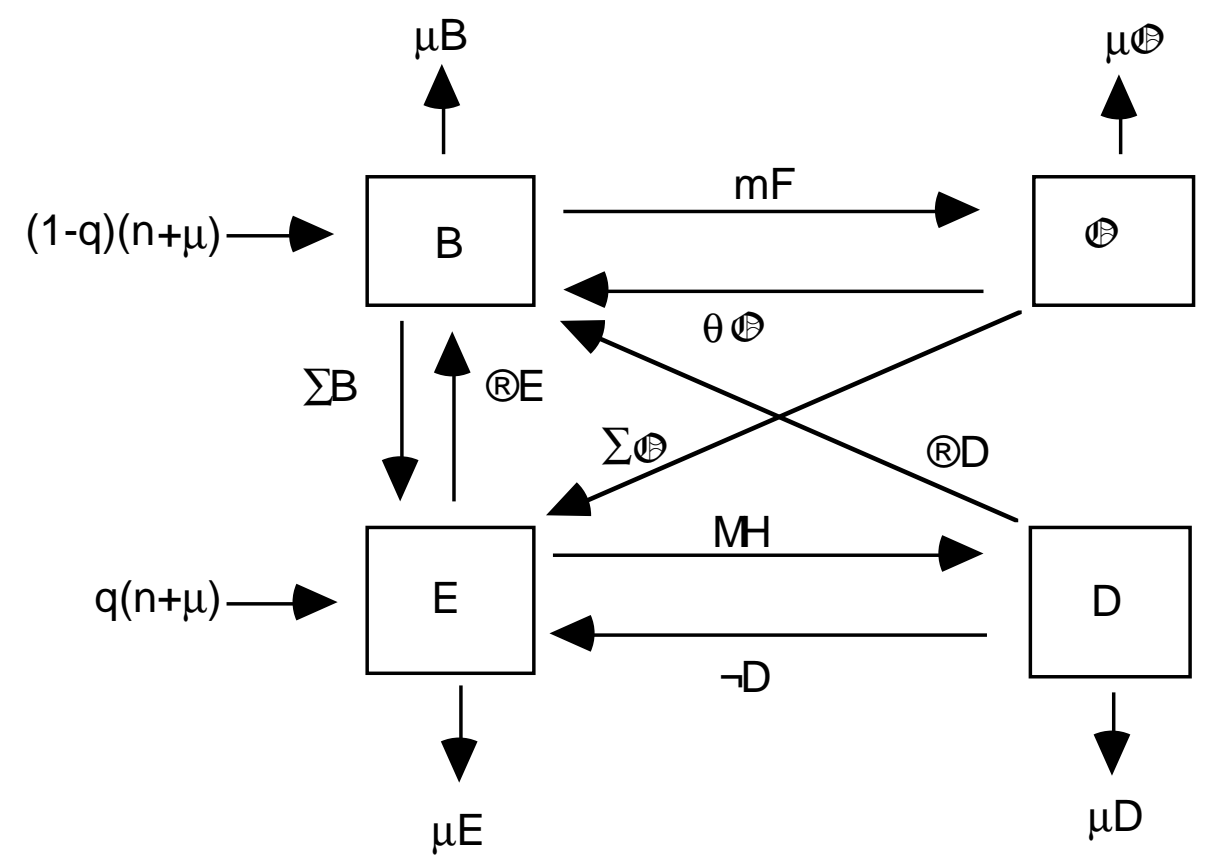

Figure 3: Flows between household states with rental and owner-occupier submarkets 
We shall omit the analysis which is tedious. Some points bear mention. Consider the modeling of the rental sector. Prospective tenants are modeled in essentially the same way as in Igarashi (1991) except that, here, rental real estate agents charge a finder's fee, which is a proportion of annual rent. Taking the market rent as given, prospective tenants choose a reservation mismatch cost $Y^{*}$. Landlords too are modeled in essentially the same way as in Igarashi (1991). They purchase houses from builders at price $P$ and then choose rent $R_{0}$ to maximize the present value of profits, taking the market rent as given. Imposition of symmetry yields an equation for the market rent, and the zero profit condition gives an equation for rental housing vacancies. Finally, the rental real estate agents' effort and entry decisions are very similar to the owneroccupier real estate agents' decisions which were analyzed earlier. Conceptually the model is no more complicated than the basic model of the previous section. Analytically, however, it is considerably more cumbersome because of the complexity of the flows between household states. This extended model could be enriched by having the household choose whether to switch between states and whether to remain in its unit while it is up for sale or rent depending on the productivity of search in each situation.

Another way in which the model is descriptively unrealistic is that it treats households as ex ante identical and houses as completely identical, except for symmetric idiosyncratic differences. In fact, households differ in tastes, income, and demographic characteristics, and houses differ in quality and location. The strengths and weaknesses of representative agent models are well-known and the points apply with double force here, because there are representative houses as well. Treating representative agents and units results in considerable algebraic simplification, but, considering the highly non-linear nature of the model, this treatment may generate substantial aggregation bias. The severity of this bias is an empirical matter. The model could be augmented to allow for housing submarkets differentiated by quality, location, structure type, and number of bedrooms, for example. And household tastes over submarkets could be represented by probabilistic choice models. Then the proportion of households in a particular income-demographic group choosing to search in different rental and owner-occupied submarkets would be calculated from the systematic expected discounted utility for the various submarkets as well as the degree and form of idiosyncrasies in tastes over these submarkets. And internal 
mobility could be modeled as triggered by income changes and demographic transitions.

These and related issues ${ }^{15}$ are important for constructing an accurate model but they are also important to understanding whether residential real estate commission rates should differ across submarkets.

We were able to sidestep modeling what it is that real estate agents do and how their presence facilitates home sales, by simply inserting the number of agents in the opportunities-to-match function. This is appropriate if, as in our model, all sales are intermediated by brokers, all brokerage contracts are the same, and all households, houses, and agents are ex ante identical. As noted in the introduction, however, there has been a trend toward greater variability in the commission rate on proportional commission contracts as well as greater diversity in contract form. There has also been a movement towards buyers' brokers. As well, household, houses, and real estate agents are not the same. And finally, a significant proportion -- between 15 and 20 percent -- of residential sales are made without broker intermediaries. When these complications are accounted for, the aggregate opportunities to match function no longer depends simply on the number of buyers, houses for sale, and agents. A richer model will have to come to grips with what it is that agents do, how they allocate their time over properties and over the duration of a listing, how their behavior is modified with alternative contractual forms, and how they signal their ability. These issues have been addressed in the many partial equilibrium papers on residential real estate brokerage. ${ }^{16}$

\subsection{Summary}

This paper developed a simple, search-based, general equilibrium model of the owner-occupied housing market with the aim of determining the socially optimal commission rate payable to real estate agents on their sales. A broad-

${ }^{15}$ A satisfactory treatment of housing demand should take into account the intertemporal nature of the household budget constraint, as well as moving costs, demographic transitions, and credit constraints, especially downpayments on owner-occupied housing. And the supply side should incorporate quality depreciation, maintenance, and rehabilitation, as well as land and hence the possibility of redevelopment.

${ }^{16}$ These issues have been discussed in various papers by Anglin (1993), Chen and Rosenthal (1994), Colwell and Yavas (1994), Geltner, Kluger and Miller (1991), Miceli (1989), Zhang (1993), and Zorn and Larsen (1986). 
brush description of the model is as follows. Households and houses differ only in idiosyncratic ways and real estate agents are identical. Upon entering the growing market, a household joins the search pool of prospective home buyers and receives opportunities to match according to an opportunities-to-match function à la Diamond / Pissarides / Hosios, which depends on the stock of buyers, homes for sale, and real estate agents, as well as agents' effort level. The household chooses the reservation quality of a match, and when it receives a satisfactory match moves immediately into its home where it remains forever. Competitive builders choose the price of housing and competitive real estate agents their effort level, with entry driving down builders' profits to zero and agents' income (with an exogenously-specified commission rate) to its opportunity level. The unique (long-run) equilibrium is characterized by the proportion of households in the search pool, the ratio of vacant houses to searchers, the number of real estate agents, the reservation match quality, agents' effort, and the price of housing.

Because builders make zero profits and real estate agents their opportunity income, all surplus accrues to households. The socially optimal commission rate therefore minimizes the expected discounted present value of an entering household's accommodation costs. The tradeoff determining the optimal commission rate is straightforward. The larger the number of agents, ceteris paribus, the greater the number of opportunities to match, which permits faster and/or better matching, but also the higher the aggregate cost of agents' time, which is reflected in a higher housing price.

While there is considerable scope for improving the basic model by adding descriptive realism, to reject it because of its simplicity would be a mistake. From a theoretical perspective, its simplicity is a virtue. The basic model highlights the essential tradeoffs underlying determination of the optimal commission rate on owner-occupied housing with a minimum of clutter. From an empirical perspective, its simplicity has the advantage that the model, augmented to include exit and internal mobility, can be estimated/calibrated on the basis of readily available data. Estimating enriched versions of the model should result in more confident estimates of the optimal commission rate but, because of data deficiencies which plague econometric work in housing, the complexity of the estimation exercise will be considerably greater. 
While we focused exclusively on the model's application to calculation of the optimal commission rate, the model, appropriately adapted, can be applied to other public policy issues vis-à-vis residential real estate brokerage. An interesting example is the recent trend, particularly in the western United States, to buyers' brokers, whereby the prospective buyer hires his own agent, in contrast to the conventional system under which the prospective buyer works with a selling agent who is an agent to the listing agent and hence a sub-agent to the seller. Using cross-sectional state data, one could estimate the aggregate opportunities-to-match function, including the number of buyers' agents and conventional agents as separate arguments. A finding that buyers' agents are more productive at the margin than conventional agents would provide evidence favoring laws and regulations which facilitate buyer brokerage. 


\section{BIBLIOGRAPHY}

Anglin, P., 1993, "A Note concerning a Competitive Equilibrium in the Market for Agents," Economics Letters 41, 247-252.

Anglin, P. and R. Arnott, 1991, "Residential Real Estate Brokerage as a PrincipalAgent Problem," Journal of Real Estate Finance and Economics 4, 99-125.

Arnott, R., 1989, "Housing Vacancies, Thin Markets and Idiosyncratic Tastes," Journal of Real Estate Finance and Economics 2, 5-30.

Blanchard, O. and P. Diamond, 1990, "The Aggregate Matching Function," in P. Diamond, ed., Growth/Productivity/Unemployment (Cambridge, MA: The M.I.T. Press), 159-201.

Blanchard, O. and P. Diamond, 1989, "The Beveridge Curve," Brookings Papers on Economic Activity 1, 1-60.

Caplin, A. and B. Nalebuff, 1991, "Aggregation and Social Choice: A Mean Voter Theorem," Econometrica 39, 1-24.

Chen, Y., and R. Rosenthal, 1994, "Asking Prices as Commitment Devices," working paper, Boston University.

Colwell, P. and A. Yavas, 1994, "Buyer Brokerage: Incentive and Efficiency Implications," working paper, University of Illinois, Office of Real Estate Research, Urbana, IL, USA.

Diamond, P., 1981, "Mobility Costs, Frictional Unemployment, and Efficiency," Journal of Political Economy 89, 798-812.

Federal Trade Commission, 1983, The Real Estate Brokerage Industry (Washington, D.C.: U.S. Government Printing Office).

Fu, Y., 1993, "Three Essays in Real Estate Economics," unpublished Ph.D. dissertation, Faculty of Commerce and Business Administration, University of British Columbia, Vancouver, Canada. 
Geltner, D., B. Kluger, and N. Miller, 1991, "Optimal Price and Selling Effort from the Perspectives of the Broker and Seller," AREUEA Journal 19, 1-24.

Hosios, A., 1990, "On the Efficiency of Matching and Related Models of Search and Unemployment," Review of Economic Studies 57, 279-298.

Igarashi, M., 1991, "A Random-Matching and Search Model of Rental Housing Markets," unpublished Ph.D. dissertation, Department of Economics, Queen's University, Kingston, Ontario, Canada.

Igarashi, M. and R. Arnott, 1995, "Rent Control, Mismatch Costs and Search Efficiency," Regional Science and Urban Economics, forthcoming.

Miceli, T., 1989, "The Optimal Duration of Real Estate Listing Contracts," AREUEA Journal 17, 267-277.

Miceli, T., 1992, "The Welfare Effects of Non-Price Competition among Real Estate Brokers," AREUEA Journal 20, 519-532.

National Association of Realtors, 1991, Home Buying and Selling Process.

Osberg, L., 1993, "Fishing in Different Pools: Job Search Strategies and Job Finding Success in Canada in the Early 1980's," Journal of Labor Economics 11, 348-368.

Peters, M., 1994, "Equilibrium Mechanisms in a Decentralized Market," Łournal of Economic Theory 64, 390-423.

Pissarides, C., 1990, Equilibrium Unemployment Theory (Cambridge, MA: Basil Blackwell).

Sirmans, C.F., G. Turnbull, and J. Benjamin, 1991, "The Markets for Housing and Real Estate Broker Services," Lournal of Housing Economics 1, 207-217.

Wheaton, W., 1990, "Vacancy, Search and Price in a Housing Market Matching Model," Lournal of Political Economy 98, 1270-1292.

Yavas, A., 1994, "Economics of Brokerage: An Overview," Џournal of Real Estate Literature 2, 169-195. 
Yavas, A., 1995, "Can Brokerage Have an Equilibrium Selection Role?" ournal of Urban Economics 37, 17-37.

Yinger, J., 1981, "A Search Model of Real Estate Brokerage," American Economic Review 71, 591-605.

Zhang, A., 1993, "An Analysis of Common Sales Agents," Canadian Journal of Economics 26, 134-149.

Zorn, T.S. and J.E. Larsen, 1986, "The Incentive Effects of Flat Fee and Percentage Commissions for Real Estate Brokers," AREUEA Journal 14, 24-47. 


\section{Appendix 1}

\section{Comparative Static Properties of Equilibrium}

Total differentiation of (8) and (9) yields

$$
\begin{aligned}
& {\left[\begin{array}{cc}
-f \tilde{m}-F \tilde{m}_{1}\left(\frac{X^{*}-\bar{X}}{r\left(b-r P-X^{*}\right)^{2}}+\frac{d\left(X^{*}-\bar{X}\right) / d X^{*}}{r\left(b-r P-X^{*}\right)}\right) & -F\left(\tilde{m}_{1} \frac{X^{*}-\bar{X}}{\left(b-r P-X^{*}\right)^{2}}+\tilde{m}_{2} \frac{1-\phi}{K}+\tilde{m}_{3} \frac{\phi}{w}\right) \\
-\frac{1}{r} \frac{d(F / f)}{d X^{*}} & 1
\end{array}\right]\left[\begin{array}{c}
d X^{*} \\
d P
\end{array}\right]} \\
& =\left[\begin{array}{l}
F\left(-\tilde{m}_{1}\left(\frac{X^{*}-\bar{X}}{r^{2}\left(b-r P-X^{*}\right)}-\frac{\left(X^{*}-\bar{X}\right) P}{r\left(b-r P-X^{*}\right)^{2}}\right)-\tilde{m}_{2}\left(\frac{(1-\phi) P-K}{r^{2} K}\right)\right) \\
-\frac{F}{r^{2} f}
\end{array}\right] d r
\end{aligned}
$$

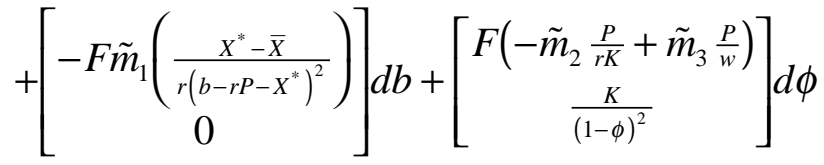

$$
\begin{aligned}
& +\left[\begin{array}{c}
F \tilde{m}_{2}\left(-\frac{1}{r K}-\frac{(1-\phi) P-K}{r K^{2}}\right) \\
\frac{1}{1-\phi}
\end{array}\right] d K+\left[\begin{array}{c}
-F \tilde{m}_{3} \frac{\phi P}{w^{2}} \\
0
\end{array}\right] d w+\left[\begin{array}{c}
F \tilde{m}_{4} \\
0
\end{array}\right] d g^{*}+\left[\begin{array}{l}
0 \\
0
\end{array}\right] d n+\left[\begin{array}{l}
1 \\
0
\end{array}\right] d \xi .
\end{aligned}
$$

Some of the comparative static derivatives can be signed on the basis of the sign pattern

$$
\begin{aligned}
& \frac{d X^{*}}{d b}>0 \quad \frac{d X^{*}}{d w}>0 \quad \frac{d X^{*}}{d g^{*}}<0 \quad \frac{d X^{*}}{d n}=0 \quad \frac{d X^{*}}{d \xi}<0 \\
& \frac{d P}{d b}>0 \quad \frac{d P}{d K}>0 \quad \frac{d P}{d w}>0 \quad \frac{d P}{d g^{*}}<0 \quad \frac{d P}{d n}=0 \quad \frac{d P}{d \xi}<0 .
\end{aligned}
$$

The signs of the other comparative static derivatives can be signed on the basis of neither the sign pattern nor a fuller analysis.

Interpretation will be facilitated by rewriting (A1.1) in terms of elasticities. Note that

$$
\varepsilon_{\tilde{m}, \tilde{B}}=\tilde{m}_{1} \tilde{B} F \quad \varepsilon_{\tilde{m}, \tilde{S}}=\tilde{m}_{2} \tilde{S} F \quad \varepsilon_{\tilde{m}, \tilde{A}}=\tilde{m}_{3} \tilde{A} F \quad \varepsilon_{\tilde{m}, \tilde{g}}=\tilde{m}_{4} g F
$$


where $\tilde{B}, \tilde{S}$, and $\tilde{A}$ now denote the normalized $B, S$, and $A$-- e.g., $\tilde{B}=\frac{X^{*}-\bar{X}}{r\left(b-r P-X^{*}\right)}$. Also, $\varepsilon_{\tilde{m}, \tilde{B}}=\varepsilon_{m, B}$ etc. Thus,

$$
\begin{aligned}
& {\left[\begin{array}{cc}
-\frac{f X^{*}}{F}-\varepsilon_{m, B}\left(\frac{X^{*}}{b-r P-X^{*}}+\varepsilon_{X^{*}-\bar{X}, X^{*}}\right) & -\varepsilon_{m, B}\left(\frac{r P}{b-r P-X^{*}}\right)-\varepsilon_{m, S}\left(\frac{(1-\phi) P}{(1-\phi) P-K}\right)-\varepsilon_{m, A} \\
-\frac{X^{*}}{r} \frac{d(F / f)}{d X^{*}} & P
\end{array}\right]\left[\begin{array}{c}
\hat{X}^{*} \\
\hat{P}
\end{array}\right]} \\
& =\left[\begin{array}{c}
-\varepsilon_{m, B}\left(1-\frac{r P}{b-r P-X^{*}}\right)-\varepsilon_{m, S} \\
-\frac{F}{r f}
\end{array}\right] \hat{r}+\left[\begin{array}{c}
\left.-\varepsilon_{m, B}\left(\frac{b}{b-r P-X^{*}}\right)\right] \hat{b} \\
0
\end{array}\right] \\
& +\left[\begin{array}{c}
-\varepsilon_{m, S}\left(\frac{\phi P}{(1-\phi) P-K}\right)+\varepsilon_{m, A} \\
\frac{K \phi}{(1-\phi)^{2}}
\end{array}\right] \hat{\phi}+\left[\begin{array}{c}
-\varepsilon_{m, S}\left(\frac{(1-\phi) P}{(1-\phi) P-K}\right) \\
\frac{K}{1-\phi}
\end{array}\right] \hat{K} \\
& +\left[\begin{array}{c}
-\varepsilon_{m, A} \\
0
\end{array}\right] \hat{w}+\left[\begin{array}{c}
\varepsilon_{m, g} \\
0
\end{array}\right] \hat{g}+\left[\begin{array}{l}
0 \\
0
\end{array}\right] \hat{n}+\left[\begin{array}{l}
1 \\
0
\end{array}\right] \hat{\xi} .
\end{aligned}
$$

The ${ }^{\wedge}$-notation denotes a proportional change in the relevant variable. The comparative static derivatives of greatest interest are with respect to the commission rate, $\phi$. Denote the determinant of the matrix premultiplying $\left[\begin{array}{ll}\hat{X}^{*} & \hat{P}\end{array}\right]^{T}$ in (A1.4) by $\Delta<0$. Then

$$
\varepsilon_{X^{*}, \phi}=\frac{\hat{X}^{*}}{\hat{\phi}}=\frac{1}{\Delta}\left|\begin{array}{cc}
-\varepsilon_{m, S}\left(\frac{\phi P}{(1-\phi) P-K}\right)+\varepsilon_{m, A} & -\varepsilon_{m, B}\left(\frac{r P}{b-r P-X^{*}}\right)-\varepsilon_{m, S}\left(\frac{(1-\phi) P}{(1-\phi) P-K}\right)-\varepsilon_{m, A} \\
\frac{K \phi}{(1-\phi)^{2}} & P
\end{array}\right|
$$

and

$$
\varepsilon_{P, \phi}=\frac{\hat{P}}{\hat{\phi}}=\frac{1}{\Delta}\left|\begin{array}{cc}
-\frac{f X^{*}}{F}-\varepsilon_{m, B}\left(\frac{X^{*}}{b-r P-X^{*}}+\varepsilon_{X^{*}-\bar{X}, X^{*}}\right) & -\varepsilon_{m, S}\left(\frac{\phi P}{(1-\phi) P-K}\right)+\varepsilon_{m, A} \\
-\frac{X^{*}}{r} \frac{d(F / f)}{d X^{*}} & \frac{K \phi}{(1-\phi)^{2}}
\end{array}\right|,
$$

which reduces to

$$
\varepsilon_{X^{*}, \phi}=\frac{1}{\Delta}\left[\varepsilon_{m, B}\left(\frac{r P K \phi}{(1-\phi)^{2}\left(b-r P-X^{*}\right)}\right)-\varepsilon_{m, S}\left(P \frac{\phi}{1-\phi}\right)+\varepsilon_{m, A}\left(P+\frac{K \phi}{(1-\phi)^{2}}\right)\right]
$$

and 


$$
\begin{gathered}
\varepsilon_{P, \phi}=\frac{1}{\Delta}\left[\frac{-f X^{*} K \phi}{F(1-\phi)^{2}}-\varepsilon_{m, B}\left(\frac{X^{*}}{b-r P-X^{*}}+\varepsilon_{X^{*}-\bar{X}, X^{*}}\right) \frac{K \phi}{(1-\phi)^{2}}-\varepsilon_{m, S}\left(\frac{\phi P}{(1-\phi) P-K}\right) \frac{X^{*}}{r} \frac{d(F / f)}{d X^{*}}\right. \\
\left.+\varepsilon_{m, A} \frac{X^{*}}{r} \frac{d(F / f)}{d X^{*}}\right] .
\end{gathered}
$$

A fair bit of the complication in the algebra derives from the generality of the form of $F(\cdot)$. When $F(\cdot)$ is uniform, $\frac{f X^{*}}{F}=1, \varepsilon_{X^{*}-\bar{X}, X^{*}}=1, \frac{d(F / f)}{d X^{*}}=1$, and $(1-\phi) P-K=\frac{X^{*}}{r}($ from (9)). Then

$$
\Delta=-P\left[1+\varepsilon_{m, B}\left(\frac{b-r P+X^{*}}{b-r P-X^{*}}\right)+\varepsilon_{m, S}(1-\phi)+\varepsilon_{m, A} \frac{X^{*}}{r P}\right]
$$

and

$$
\begin{aligned}
& \varepsilon_{X^{*}, \phi}=-\frac{P}{\Delta}\left[-\varepsilon_{m, B}\left(\frac{r K \phi}{(1-\phi)^{2}\left(b-r P-X^{*}\right)}\right)+\varepsilon_{m, S} \frac{\phi}{1-\phi}-\varepsilon_{m, A}\left(1+\frac{K \phi}{P(1-\phi)^{2}}\right)\right] \\
& \varepsilon_{P, \phi}=-\frac{P}{\Delta}\left[\frac{K \phi}{P(1-\phi)^{2}}+\varepsilon_{m, B}\left(\frac{b-r P}{b-r P-X^{*}}\right) \frac{K \phi}{P(1-\phi)^{2}}+\varepsilon_{m, S} \phi-\varepsilon_{m, A} \frac{X^{*}}{r P}\right] .
\end{aligned}
$$


Appendix 2

Derivation of Analogs to (1) and (2) in Section 3.1

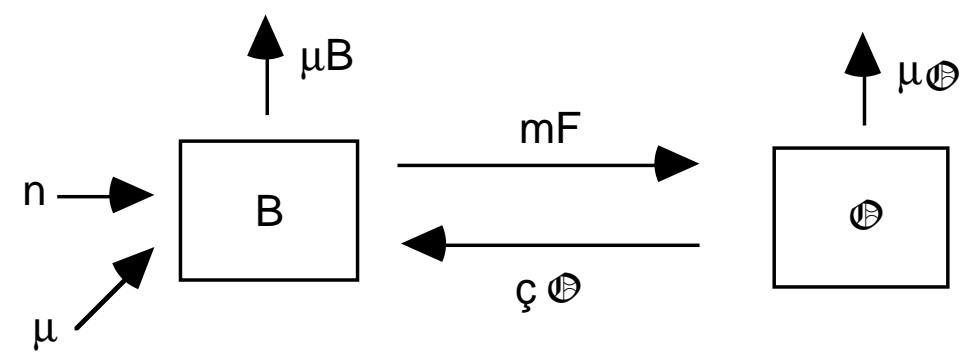

The flows are given in the above diagram. We have that

$$
\begin{aligned}
& \dot{B}=n+\mu \mathbb{\bigoplus}-m F+\theta \mathbb{} \\
& B+\mathbb{\theta}=1 \\
& \dot{B}=n B
\end{aligned}
$$

(A2.1.1) describes the evolution of $B$; (A2.1.2) indicates that population is normalized at one; and (A2.1.3) is the steady-state condition. Substituting (A2.1.2) and (A2.1.3) into (A2.1.1) yields

$$
(n+\theta+\mu)(1-B)-m F=0,
$$

which is the analog to (1) presented in the body of the paper.

Let $C^{\oplus}$ be the expected present value of accommodation for a household in owner-occupied housing, from the perspective of a household in the search pool. Then

$$
C^{B}=b d t+\left[C^{B}\left(1-\mu d t-\frac{m F}{B} d t\right)+C^{B}(\mu d t)+\left(C^{\oplus}+P\right)\left(\frac{m F}{B} d t\right)\right] e^{-r d t}
$$

which reduces to

$$
0=b+C^{B}\left(-\frac{m F}{B}-r\right)+\left(C^{\oplus}+P\right)\left(\frac{m F}{B}\right) .
$$


Similarly,

$$
C^{\oplus}=\bar{X} d t+\left[C^{\oplus}(1-\mu d t-\theta d t)+\left(C^{B}-(1-\phi) P \frac{\frac{m F}{S}}{\frac{m F}{S}+r}\right)(\mu+\theta) d t\right] e^{-r d t} .
$$

The last term takes into account that a household that exits owner-occupied housing and enters the search pool in this or some other market expects to receive $\frac{(1-\phi) P \frac{m F}{S}}{\frac{m F}{S}+r}$ from the sale of its house (recall the equation before (3)). (A2.1.7) reduces to

$$
0=\bar{X}-C^{\oplus}(\mu+\theta+r)+\left(C^{B}-\frac{(1-\phi) P \frac{m F}{S}}{\frac{m F}{S}+r}\right)(\mu+\theta)
$$

or

$$
C^{\oplus}=\frac{\bar{X}}{\mu+\theta+r}+\frac{\mu+\theta}{\mu+\theta+r}\left(C^{B}-\frac{(1-\phi) P \frac{m F}{S}}{\frac{m F}{S}+r}\right) .
$$

Substituting (A2.1.8) into (A2.1.6) yields

$$
\begin{aligned}
0=b+ & C^{B}\left(-\frac{m F}{B}-r\right)+\frac{\bar{X}}{r}\left(\frac{r}{\mu+\theta+r}\right) \frac{m F}{B}+C^{B}\left(\frac{\mu+\theta}{\mu+\theta+r}\right) \frac{m F}{B} \\
& -\left(\frac{\mu+\theta}{\mu+\theta+r}\right)\left(\frac{\frac{m F}{S}}{\frac{m F}{S}+r}\right)(1-\phi) P\left(\frac{m F}{B}\right)+P \frac{m F}{B},
\end{aligned}
$$

which reduces to

$$
\begin{gathered}
C^{B}=\frac{b}{r}\left(\frac{\mu+\theta+r}{\frac{m F}{B}+\mu+\theta+r}\right)+\frac{\bar{X}}{r}\left(\frac{\frac{m F}{B}}{\frac{m F}{B}+\mu+\theta+r}\right) \\
+\frac{P \frac{m F}{B}\left[\left(\frac{m F}{S}\right)\left(1+\phi\left(\frac{\mu+\theta}{r}\right)\right)+(\mu+\theta+r)\right]}{\left(\frac{m F}{S}+r\right)\left(\frac{m F}{B}+\mu+\theta+r\right)} .
\end{gathered}
$$

Define

$$
\Xi \equiv \frac{\left(\frac{m F}{S}\right)\left(1+\phi\left(\frac{\mu+\theta}{r}\right)\right)+\mu+\theta+r}{\frac{m F}{S}+r}>1 .
$$


Then (A2.1.9) can be written more simply as

$$
C^{B}=\left(\frac{\mu+\theta+r}{\frac{m F}{B}+\mu+\theta+r}\right) \frac{b}{r}+\left(\frac{\frac{m F}{B}}{\frac{m F}{B}+\mu+\theta+r}\right)\left(\frac{\bar{X}}{r}+\Xi P\right) .
$$

This equation indicates that expected discounted accommodation costs when in the search pool are a weighted average of the discounted costs of being in the search pool and the expected discounted costs of being in owner-occupied housing, where the weights are the discounted expected proportion of time in the search pool and in owner-occupied housing.

Let $C^{\oplus}\left(X^{*}\right)$ be the expected present value of accommodation for a household which buys a house of reservation mismatch quality. By an argument analogous to that used to derive $C^{\oplus}$,

$$
C^{\oplus}\left(X^{*}\right)=\frac{r}{\mu+\theta+r}\left(\frac{X^{*}}{r}\right)+\frac{\mu+\theta}{\mu+\theta+r}\left(C^{B}-\frac{(1-\phi) P \frac{m F}{S}}{\frac{m F}{S}+r}\right) .
$$

The reservation purchase rule is that $C^{B}=C^{\mathscr{\Theta}}\left(X^{*}\right)+P$. Combining this with (A2.1.12) yields

$$
\begin{gathered}
C^{B}=\frac{X^{*}}{r}-\frac{(1-\phi) P \frac{m F}{S}}{\frac{m F}{S}+r}\left(\frac{\mu+\theta}{r}\right)+\left(\frac{\mu+\theta+r}{r}\right) P \\
=\frac{X^{*}}{r}+P \Xi .
\end{gathered}
$$

Equating (A2.1.13) and (A2.1.11) yields the analog to (2) given in the main body of the paper, which can be rewritten as

$$
\left(\frac{\mu+\theta+r}{\frac{m F}{B}+\mu+\theta+r}\right)\left(\frac{b}{r}-P \Xi-\frac{X^{*}}{r}\right)-\left(\frac{\frac{m F}{B}}{\frac{m F}{B}+\mu+\theta+r}\right)\left(\frac{X^{*}}{r}-\frac{\bar{X}}{r}\right)=0 .
$$

Substituting out $B$ using (A2.1.4) gives

$$
(\mu+\theta+r)\left(\frac{b}{r}-P \Xi-\frac{X^{*}}{r}\right)-\frac{m F(n+\theta+\mu)}{n+\theta+\mu-m F}\left(\frac{X^{*}}{r}-\frac{\bar{X}}{r}\right)=0 .
$$

Combining this equation with (3) - (5) yields two equations, (4) and 


$$
(\mu+\theta+r)\left(\frac{b}{r}-P \mathfrak{A}-\frac{X^{*}}{r}\right)-\frac{m F(n+\theta+\mu)}{n+\theta+\mu-m F}\left(\frac{X^{*}}{r}-\frac{\bar{X}}{r}\right)=0,
$$

in two unknowns, where

$$
\mathfrak{A}=\frac{r+\mu+\theta}{r}-\frac{(\mu+\theta) K}{r P}
$$

and

$$
m=m\left(1-\frac{m F\left(X^{*}\right)}{n+\theta+\mu}, \frac{((1-\phi) P-K) m F\left(X^{*}\right)}{r K}, \frac{\phi m P F\left(X^{*}\right)}{w}, g^{*}\right)
$$




\section{Notational Glossary}

$\mathfrak{A}$

A occupied

$A^{\prime}$ submarket

B

$b$

$C^{B}$

$C(g)$

$c_{0}, c$

D

E

$\mathfrak{E}$

$F(X), f(X)$

$\mathfrak{J}(X)$

$g$

$g^{\prime}$

$G(\cdot)$

$H(Y), h(Y)$

$I(\cdot)$

K

$M, M(\cdot)$ market, rental intermediate variable

proportion of households that are real estate agents (in ownersubmarket)

proportion of households that are real estate agents in the rental proportion of households that are home buyers per-period search costs for a homebuyer expected present value of accommodation costs for homebuyers real estate agent's cost of effort (in owner-occupied submarket) constants proportion of households that are renters proportion of households that are in the rental search pool expectations operator

c.d.f. and p.d.f. of $X$, respectively integral of $F(X)$ real estate agent effort (in owner-occupied submarket) real estate agent effort in rental submarket intermediate function

c.d.f. and p.d.f. of $Y$, respectively intermediate function construction cost of a home aggregate opportunities to match per period in rental housing matching function 


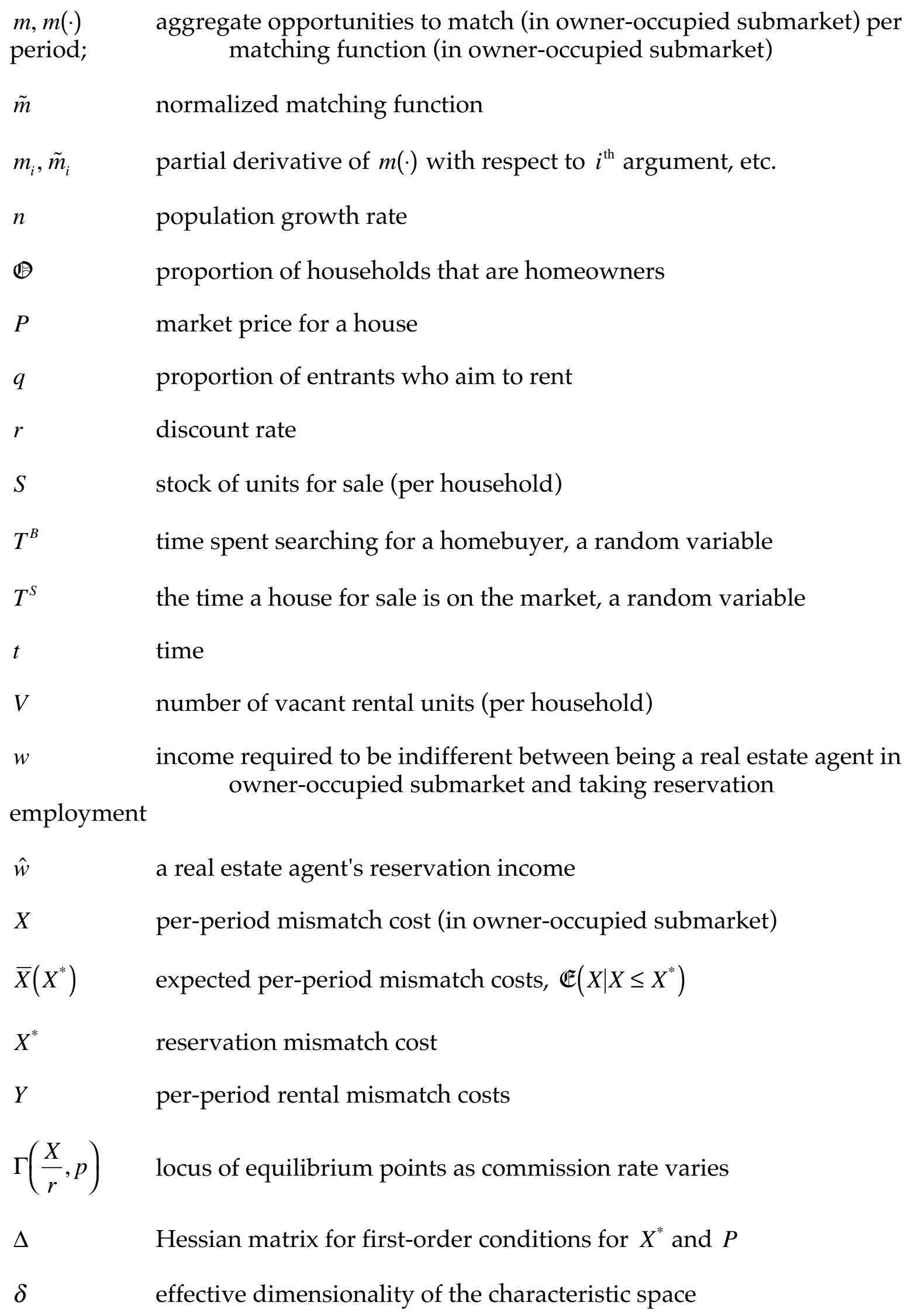




$\begin{array}{ll}\varepsilon_{i, j} & \text { elasticity of } i \text { with respect to } j \\ \theta & \text { proportional Poisson mobility rate with owner-occupied housing } \\ \lambda & \text { proportional Poisson mobility rate within rental sector } \\ \mu & \text { Poisson exit rate } \\ \xi & \text { parameter characterizing efficiency of matching process } \\ \Pi & \text { builder's profits } \\ \rho & \text { proportional Poisson rate at which a household in the rental } \\ \text { submarket } & \text { switches to owner-occupied search pool } \\ \sigma(\cdot) & \text { aggregate sales function }(\equiv F(\cdot) m(\cdot)) \\ \phi & \text { commission rate } \\ \omega & \text { proportional Poisson rate at which a household in the owner- } \\ \text { occupied } & \text { submarket switches to the rental submarket } \\ \Xi & \text { intermediate variable }\end{array}$




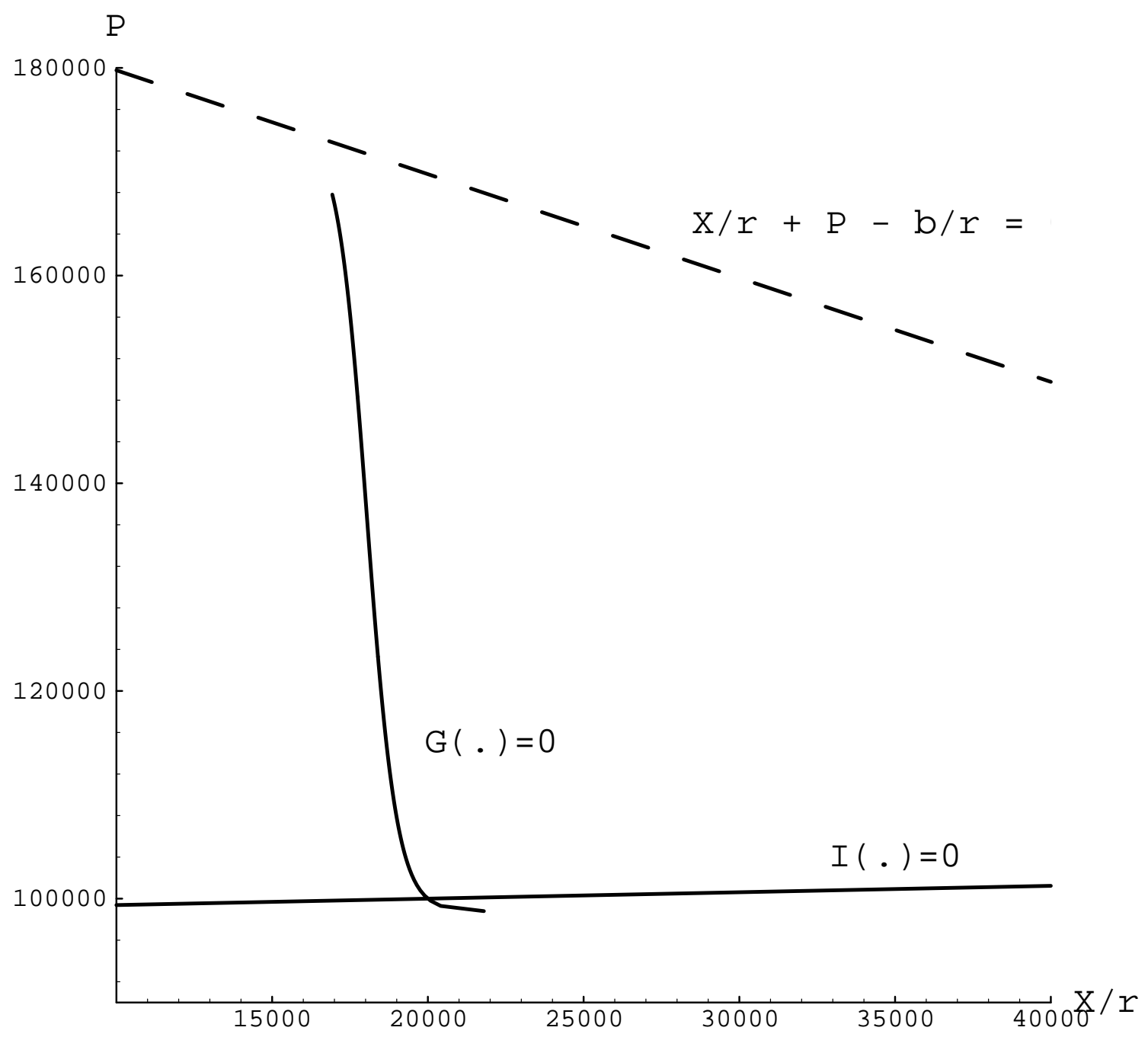

Figure 1: Determination of Equilibrium 


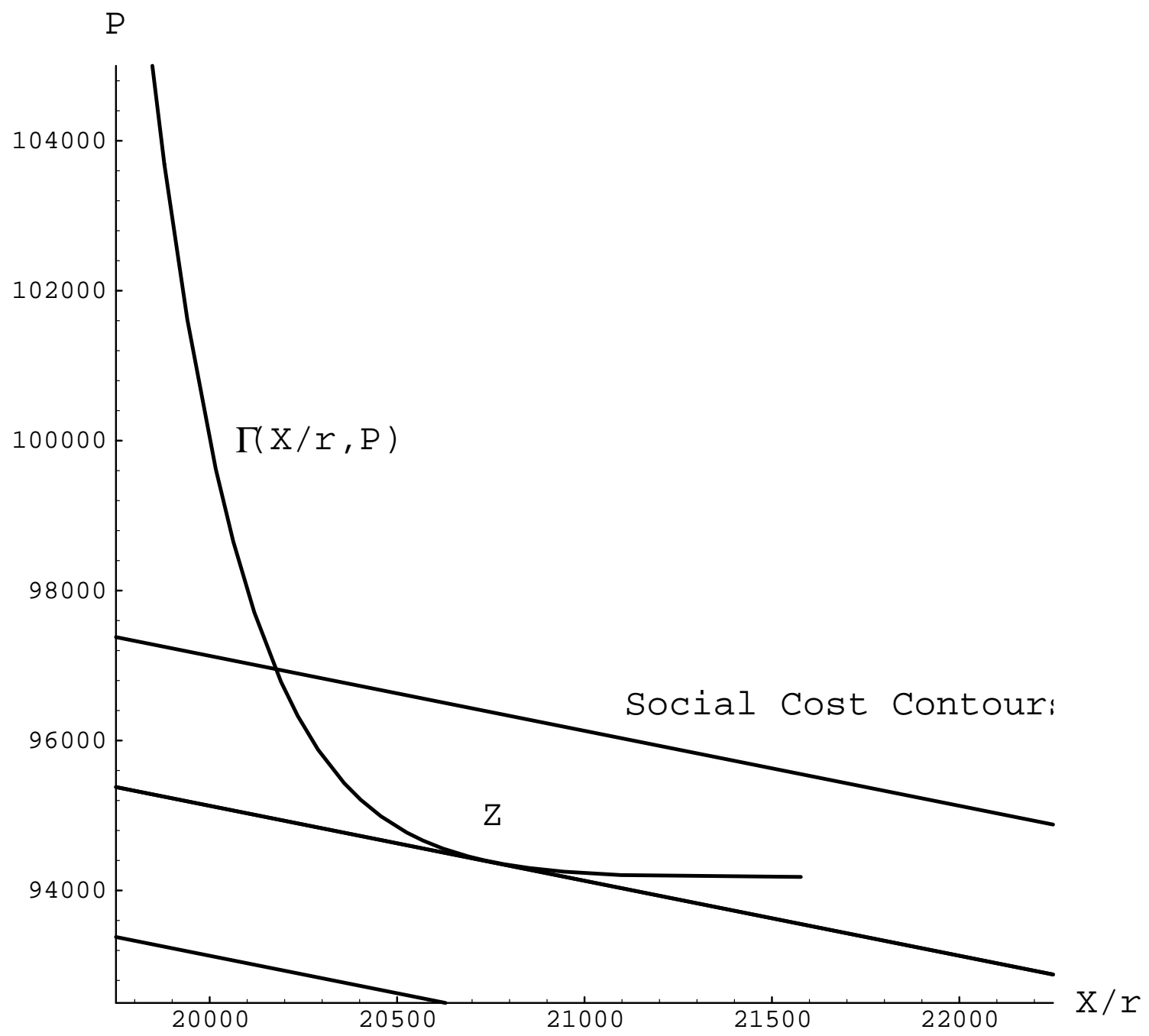

Figure 2: Determination of Optimal Commission Rate 